\title{
Use of Extracellular Vesicles for Cell-Free Regenerative Medicine in Osteochondral and Bone-Related Therapies
}

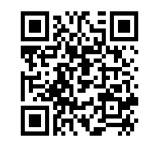

\author{
Forteza-Genestra, M.A. ${ }^{+1,2}$; Antich-Rosselló, M. ${ }^{+1,2}$; Monjo, M.*1,2; Ramis, J.M.*1,2 \\ ${ }^{1}$ Group of Cell Therapy and Tissue Engineering, Research Institute on Health Sciences (IUNICS), University of Balearic Islands, Spain \\ ${ }^{2}$ Balearic Islands Health Research Institute (IdISBa), Spain
}

${ }^{+}$Both authors have equally contributed to this work.

Received: March 13, 2018; Published: March 27, 2018

*Corresponding author: Marta Monjo and Joana Maria Ramis, Group of Cell Therapy and Tissue Engineering, Research Institute on Health Sciences (IUNICS), University of Balearic Islands, Palma, Balearic Islands Health Research Institute (IdISBa), Spain, Email: marta.monjo@uib.es, joana.ramis@ uib.es

\begin{abstract}
Abbreviations: C28/I2: Human Primary Chondrocytes Cell Line; FLS: Fibroblast Like Synoviocyte; HASC: Human adipose stem cells; hBMMSC: Human Bone Marrow Mesenchymal Stem Cells; hESC: Human Embryonic Stem Cells; hiPS-MSC: Human-Induced Pluripotent Stem CellDerived Mesenchymal Stem Cells; hMSC: Primary Human Marrow Derived Stromal Cells; HUVEC: Human Umbilical Vein Endothelial Cells; mBM-MSC: Murine Bone Marrow Mesenchymal Stem Cells; MC3T3-E1: Murinepreosteoblastic Cell Line; RA: Rheumatoid Arthritis; SMSCS: Synovial Mesenchymal Stem Cells
\end{abstract}

\section{Introduction}

The tissue engineering paradigm considers cells, signals and scaffolds as the major elements of tissue engineering approaches to repair and/or regenerate tissues [1]. Unexpectedly, a paradigm shift is taking place in this field by the only use of extracellular vesicles (EVs) to deliver the right signals to the damaged tissue. In recent years, EVs role in intercellular signalling has begun to emerge [2]. EVs range in size from 30 to $1000 \mathrm{~nm}$ and can be derived from the endosomal system (exosomes, 70-150 nm) or produced by outward budding of the plasma membrane (micro vesicles, 100-1000 nm) $[3,4]$. All EVs are enriched in proteins, lipids, and nucleic acids (DNA, mRNA, miRNA, tRNA) that can be delivered to recipient cells for cellto-cell communication [5]. In fact, EVs have recently evolved to be vital components of cell-based therapies based on the observations that the beneficial effects of cell therapies could not be attributed to cell survival and differentiation, leading to the thought that cell therapies act in a paracrine rather than in a cellular manner [6]. This shift was based on in vivo data showing that stem cell engraftment and differentiation at injury sites was very low and transient [7-11] And on the observation that conditioned media from cultured stem cells reproduces some of the beneficial effects of intact cells $[12,13]$. This paracrine effect exerted by stem cells would depend on their capacity to secrete soluble factors [14], but also, by the release of EVs [15]. In particular, preclinical models studying graft versus host disease, acute kidney failure and ischemic stroke suggest that EVs exert the stem cells' therapeutic effects [16-18].

These findings lead to the hypothesis that EVs could be a cell-free alternative for regenerative medicine [19]. EVs therapy presents several benefits over cell-based therapies, such as the possibility to sterilize the EVs by filtration, their off-the-shelf use, and the variety of available storage buffers or the simple requests on storage conditions [20]. Different cell sources for EVs isolation are being investigated for treatment of a wide variety of diseases and the evaluation of all recent work on EVs for regenerative medicine is beyond the scope of this mini-review and has extensively been reviewed by others [21-23]. Here, we focus on the use of EVs as a cellfree treatment in osteochondral and bone-related diseases (Table 1). For osteochondral diseases, mainly Mesenchymal Stem Cells (MSC) - Synovial Stem Cells (SMSCS) [24], human Bone Marrow Stem Cells (hBM-MSC) [25], Human Embryonic Stem Cells (hESC) [26] or Murine Bone Marrow Mesenchymal Stem Cells (mBM-MSC) [27] - but also neutrophils or synovial fluid [28,29] have been used as source of exosomes and microvesicles. The osteochondrogenic effect of these EVs has been reported using in vitro, in vivo or even ex vivo models, showing a better fracture healing and tissue repair when wounds in cartilage are treated with exosomes $[25,26]$ and a modulation of inflammation when wounds are treated with microvesicles derived from neutrophils and synovial fluids.

For bone-related diseases, exosomes derived from MSC or from induced Pluripotent Stem Cells (iPSC) have been used, reporting osteogenic effects in vitro [30-32] and /or in vivo [25,30-33], using different models. Nevertheless, exosomes from other sources are also being studied, such as Adipose Stem Cells (HASC) [34], mineralizing preosteoblasts [35], osteosarcoma cells [25], monocytes [36] or dendritic cells [37]. Two important examples of lack of osteogenic activity are described for exosomes derived from osteosarcoma and dendritic cells exosomes derived. Nevertheless, 
dendritic cells show an important role in MSC recruitment despite this lack of osteogenic nor chondrogenic activity [37]. Nevertheless, dendritic cells show an important role in MSC recruitment despite this lack of osteogenic nor chondrogenic activity [37]. What is more, for treatment of bone related diseases, the most recent advances result from the combination of exosomes with already existing biomaterials, such as collagen membranes [32], tricalcium phosphate [30,33] or polymeric scaffolds [34], pointing out that further studies formulating new biomaterials with exosomes will play a key role in the field of bone regenerative therapies in the next years.

In conclusion, the use of extracellular vesicles is emerging as a shift in the basic paradigm in tissue engineering and regenerative medicine as a strategy for cell-free therapies.

Table 1: EVs sources and therapeutic targets for cell-free regenerative medicine in osteochondral and bone-related therapies.

\begin{tabular}{|c|c|c|c|c|}
\hline Source & Therapeutic Target & EV subtype & Study model & References \\
\hline SMSCS & Osteoarthritis & Exosomes & In vivo (rat) & [24] \\
\hline hBM-MSC \& HOS & $\begin{array}{l}\text { Endochondral ossification } \\
\text { in bone fracture }\end{array}$ & Exosomes & In vivo (mouse) & {$[25]$} \\
\hline hESC & Osteochondral defects & Exosomes & In vivo (rat) & {$[26]$} \\
\hline mBM-MSC & $\begin{array}{l}\text { Protection from cartilage } \\
\text { and bone degradation }\end{array}$ & Exosomes and microvesicles & In vitro (mouse) & [27] \\
\hline $\begin{array}{l}\text { Neutrophils (from control } \\
\text { and arthritis patients) }\end{array}$ & Inflammation in the synovia & Microvesicles & $\begin{array}{l}\text { In vitro (Macrophage-FLS Co-Cultures) In } \\
\text { vivo (mouse) }\end{array}$ & [28] \\
\hline $\begin{array}{l}\text { Human RA Synovial Fluid \& } \\
\text { Neutrophils }\end{array}$ & Rheumatoid arthritis & Microvesicles & $\begin{array}{c}\text { In vitro (C28/I2 cell line) In vivo (mouse) } \\
\text { Ex vivo (rat cartilage explants) }\end{array}$ & [29] \\
\hline hiPSC-MSC & Osteoporosis & Exosomes & $\begin{array}{l}\text { In vitro (osteopenic rat's BMSC) In vivo } \\
\text { (osteopenic rat) }\end{array}$ & {$[30]$} \\
\hline Mutant BMSC & Femoral head necrosis & Exosomes & $\begin{array}{l}\text { In vitro (2D and 3D HUVEC) In vivo } \\
\text { (rabbit) }\end{array}$ & {$[31]$} \\
\hline hMSCs & Bone regeneration model & Exosomes & $\begin{array}{l}\text { In vitro (2D and 3D hMSC) In vitro } \\
\text { (mouse) }\end{array}$ & [32] \\
\hline hiPS-MSC & Bone defects & Exosomes & In vivo (rats) & [33] \\
\hline HASC & Bone defects & Exosomes & In vitro (hBMSC) In vivo (mouse) & {$[34]$} \\
\hline Mineralizing MC3T3-E1 & Bone regeneration model & Exosomes & $\begin{array}{l}\text { In vitro (ST2 mouse BMSC) In vivo } \\
\text { (mouse) }\end{array}$ & {$[35]$} \\
\hline Human monocytes & Bone regeneration model & Exosomes & In vitro (hMSC) & {$[36]$} \\
\hline $\begin{array}{l}\text { Primary human dendritic } \\
\text { cells }\end{array}$ & Bone regeneration model & Exosomes enriched Evs & In vitro (hMSC) & {$[37]$} \\
\hline
\end{tabular}

\section{Acknowledgement}

This work was supported by the Instituto de Salud Carlos III (PI17/01605 and CP16/00124) and the Vicepresidència I Conselleriad'Innovació, Recerca I Turisme del Govern de les IllesBalears (FPI/2046/2017).

\section{References}

1. Nerem RM, Schutte SC (2014) The Challenge of Imitating Nature. In Princ. Tissue Eng. Fourth Edi, Elsevier: pp. 9-24.

2. Théry C (2011) Exosomes: secreted vesicles and intercellular communications. F1000 Biol Rep 3:15.

3. Fais S, O Driscoll L, Borras FE, Buzas E, Camussi G, et al. (2016) EvidenceBased Clinical Use of Nanoscale Extracellular Vesicles in Nanomedicine. ACS Nano 10(4): 3886-3899.

4. Yáñez Mó M, Siljander PRM, Andreu Z, Zavec AB, Borràs FE, et al. (2015) Biological properties of extracellular vesicles and their physiological functions. J Extracell Vesicles 4: 27066.

5. Penfornis P, Vallabhaneni KC, Whitt J, Pochampally R (2016) Extracellular vesicles as carriers of microRNA, proteins and lipids in tumor microenvironment. Int J Cancer 138: 14-21.

6. Caplan AI, Correa D (2011) The MSC: An injury drugstore. Cell Stem Cell 9:11-5.
7. Ma S, Xie N, Li W, Yuan B, Shi Y (2014) Immunobiology of mesenchymal stem cells. Cell Death Differ 21: 216-225.

8. Bennet L, Tan S, Van Den Heuij L, Derrick M, Groenendaal F, et al. (2012) Cell therapy for neonatal hypoxia-ischemia and cerebral palsy. Ann Neurol 71: 589-600.

9. Chen J, Li Y, Katakowski M, Chen X, Wang L, et al. (2003) Intravenous bone marrow stromal cell therapy reduces apoptosis and promotes endogenous cell proliferation after stroke in female rat. J Neurosci Res 73: 778-786.

10. Chimenti I, Smith RR, Li TS, Gerstenblith G, Messina E, et al. (2010) Relative roles of direct regeneration versus paracrine effects of human cardiosphere-derived cells transplanted into infarcted mice. Circ Res 106: 971-980.

11. Katsha AM, Ohkouchi S, Xin H, Kanehira M, Sun R, et al. (2011) Paracrine factors of multipotent stromal cells ameliorate lung injury in an elastaseinduced emphysema model. Mol Ther 19: 196-203.

12. Lee JW, Fang X, Gupta N, Serikov V, Matthay MA (2009) Allogeneic human mesenchymal stem cells for treatment of E. coli endotoxin-induced acute lung injury in the ex vivo perfused human lung. Proc Natl Acad Sci U S A 106:16357-16362.

13. Timmers L, Lim SK, Arslan F, Armstrong JS, Hoefer IE, et al. (2008) Reduction of myocardial infarct size by human mesenchymal stem cell conditioned medium. Stem Cell Res 1: 129-137. 
14. Caplan AI, Dennis JE (2006) Mesenchymal stem cells as trophic mediators. J Cell Biochem 98:1076-1084.

15. Heldring N, Mäger I, Wood MJA, Le Blanc K, Andaloussi SEL (2015) Therapeutic Potential of Multipotent Mesenchymal Stromal Cells and Their Extracellular Vesicles. Hum Gene Ther 26: 506-517.

16. Bruno S, Camussi G (2013) Role of mesenchymal stem cell-derived microvesicles in tissue repair. Pediatr Nephrol 28: 2249-2254

17. Bruno S, Grange C, Deregibus MC, Calogero RA, Saviozzi S, et al. (2009) Mesenchymal Stem Cell-Derived Microvesicles Protect Against Acute Tubular Injury. J Am Soc Nephrol 20: 1053-1067.

18. Doeppner TR, Herz J, Gorgens A, Schlechter J, Ludwig AK, et al. (2015) Extracellular Vesicles Improve Post-Stroke Neuroregeneration and Prevent Postischemic Immunosuppression. Stem Cells Transl Med 4: $1131-1143$

19. Rani S, Ryan AE, Griffin MD, Ritter T (2015) Mesenchymal Stem Cell-derived Extracellular Vesicles: Toward Cell-free Therapeutic Applications. Mol Ther 23: 812-823.

20. Gimona M, Pachler K, Laner-Plamberger S, Schallmoser K, Rohde E (2017) Manufacturing of Human Extracellular Vesicle-Based Therapeutics for Clinical Use. Int J Mol Sci 18(6): 1190.

21. Pham P Van (2017) Concise review: Extracellular vesicles from mesenchymal stem cells as cellular therapy. Biomed Res Ther 4: 15621573.

22. Lener T, Gimona M, Aigner L, Börger V, Buzas E, et al. (2015) Applying extracellular vesicles based therapeutics in clinical trials-an ISEV position paper. J Extracell Vesicles 4: 30087.

23. Phinney DG, Pittenger MF (2017) Concise Review: MSC-Derived Exosomes for Cell-Free Therapy. Stem Cells 35: 851-858.

24. Tao SC, Yuan T, Zhang YL, Yin WJ, Guo SC, Zhang CQ (2017) Exosomes derived from miR-140-5p-overexpressing human synovial mesenchymal stem cells enhance cartilage tissue regeneration and prevent osteoarthritis of the knee in a rat model. Theranostics 7: 180-195.

25. Furuta T, Miyaki S, Ishitobi H, Ogura T, Kato Y, et al (2016) Mesenchymal Stem Cell-Derived Exosomes Promote Fracture Healing in a Mouse Model. Stem Cells Transl Med 5: 1620-1630.

26. Zhang S, Chu WC, Lai RC, Lim SK, Hui JHP, et al. (2016) Exosomes derived from human embryonic mesenchymal stem cells promote osteochondral regeneration. Osteoarthr Cartil 24: 2135-2140.
27. Cosenza S, Ruiz M, Toupet K, Jorgensen C, Noël D (2017) Mesenchymal stem cells derived exosomes and microparticles protect cartilage and bone from degradation in osteoarthritis. Sci Rep 7: 16214.

28. Rhys HI, Dell Accio F, Pitzalis C, Moore A, Norling L V, et al. (2018) Neutrophil Microvesicles from Healthy Control and Rheumatoid Arthritis Patients Prevent the Inflammatory Activation of Macrophages. EBioMedicine S2352-3964(18): 30052-30055.

29. Headland SE, Jones HR, Norling LV, Kim A, Souza PR, et al. (2015) Neutrophil-derived microvesicles enter cartilage and protect the joint in inflammatory arthritis. Sci Transl Med 7: 315ra190.

30. Qi X, Zhang J, Yuan H, Xu Z, Li Q, et al. (2016) Exosomes Secreted by Human-Induced Pluripotent Stem Cell-Derived Mesenchymal Stem Cells Repair Critical-Sized Bone Defects through Enhanced Angiogenesis and Osteogenesis in Osteoporotic Rats. Int J Biol Sci 12: 836-849.

31. Li H, Liu D, Li C, Zhou S, Tian D, et al. (2017) Exosomes secreted from mutant-HIF-1 $\alpha$-modified bone-marrow-derived mesenchymal stem cells attenuate early steroid-induced avascular necrosis of femoral head in rabbit. Cell Biol Int 41: 1379-1390.

32. Narayanan R, Huang CC, Ravindran S (2016) Hijacking the Cellular Mail: Exosome Mediated Differentiation of Mesenchymal Stem Cells. Stem Cells Int 2016: 3808674.

33. Zhang J, Liu X, Li H, Chen C, Hu B, et al. (2016) Exosomes/tricalcium phosphate combination scaffolds can enhance bone regeneration by activating the PI3K/Akt signaling pathway. Stem Cell Res Ther 7: 136.

34. Li W, Liu Y, Zhang P, Tang Y, Zhou M, et al. (2018) Tissue-Engineered Bone Immobilized with Human Adipose Stem Cells-Derived Exosomes Promotes Bone Regeneration. ACS Appl Mater Interfaces10: 5240-5254.

35. Cui Y, Luan J, Li H, Zhou X, Han J (2016) Exosomes derived from mineralizing osteoblasts promote ST2 cell osteogenic differentiation by alteration of microRNA expression. FEBS Lett 590: 185-192.

36. Ekström K, Omar O, Granéli C, Wang X, Vazirisani F, et al. (2013) Monocyte exosomes stimulate the osteogenic gene expression of mesenchymal stem cells. PLoS One 8: e75227.

37. Silva AM, Almeida MI, Teixeira JH, Maia AF, Calin GA, et al. (2017) Dendritic Cell-derived Extracellular Vesicles mediate Mesenchymal Stem/Stromal Cell recruitment. Sci Rep 7: 1667.

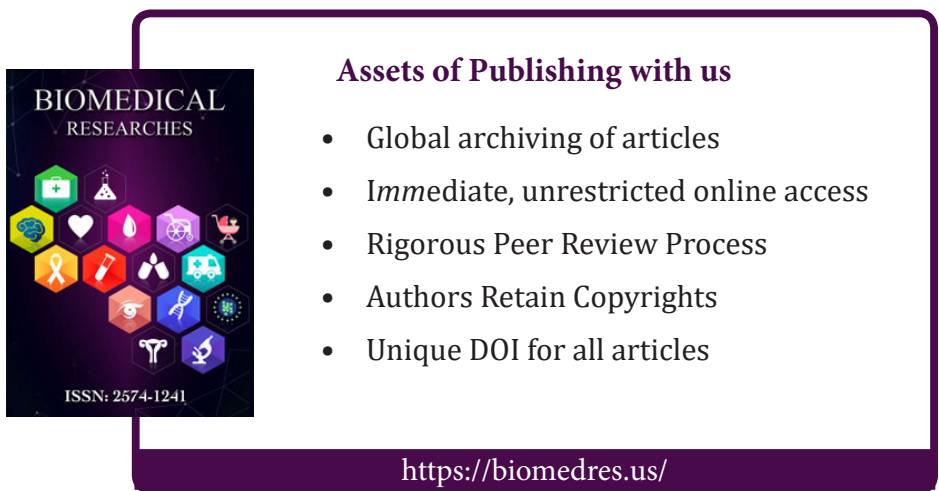

